\title{
The Main Factors Change of Economic Growth , Regional Economic Disparities in China and Economic Transformation of China
}

\author{
Yaling Li \\ Business and Tourism Management School, Yunnan University, Kunming, Yunnan, China \\ 1401321642@qq.com
}

\begin{abstract}
Keywords: Growth factors, Growth phase, Regional economic disparity, Economic transformation.
\end{abstract}
\begin{abstract}
This paper, based on regional panel data from 2003 to 2015 in China, uses mixed estimate dynamic growth model to empirically test the relationship between the main factors change of economic growth and regional economic disparity and economic transformation in China. The empirical results show that the power structure of growth factors has changed. Human capital has become the first driving force for economic growth, and physical capital's effects still cannot be ignored in the long term, and the role of labor take a back seat in the end. Total factor productivity is an important factor that affects economic growth. The factor allocation is unbalanced within regions. Human capital and total factor productivity are important factors which cause the regional economic differences. This indicates that China is transforming from after-Malthusian growth phase to a modern economic growth phase, in which the change of the population structure will play an important role. Chinese economic transformation should be advanced according to the order based on the reality of regional economic disparity. To increase human capital investment and improve total factor productivity are inevitable choices for China to succeed in achieving transformation and long-term economic growth target.
\end{abstract}

\section{Introduction}

Economic transformation is an inevitable problem which a country will experience in the process of its long-term economic development. According to international experience, both developed countries and new industrialized countries achieved sustained and rapid development through the economic transformation and upgrading.

From the perspective of the transformation of economic growth mode, the existing literatures mainly regard factor determinism, represented by neoclassical growth theory and endogenous growth theory, as theoretical basis to explore how to transform from extensive growth mode to intensive growth mode. But factor determinism can only explain the growth of a local phase within the multiple phases of development in human history, while it cannot answer how the development process of human history take off gradually from Malthusian trap into the sustained economic growth phase within a unified theoretical framework.

However, the change of economic growth phase is the common phenomenon in the process of world economic development. How to achieve long-term sustainable economic growth is a theme that each country concerns during the change of economic growth phase. In order to explain the endogenous transformation process between different developmental phases of the historical process of human social development by using economic growth theory, and better explain the widening income gap within different countries, at the same time reasonably explain the demographic transition and the great divergence phenomenon with the endogenous transformation of the economy, Galor and Weil (2000) firstly combined Malthusian theory with modern economic growth theory to try the creation of unified growth theory framework.

Unified growth theory holds that the influence factors of economic growth are five important variables. They are labor flowing from low productivity sector to high productivity sector, demographic dividend, capital investment, human capital investment and the proportion of the working population in total population. A country's economic growth will change from one phase to new phase. A country's modernization process will experience three phases of growth in turn: 
dominated by agriculture, dominated by modern manufacturing and service industry, and dominated by human capital. The realization of the long-term economic growth is the jump from lower phase to higher phase. In different growth phase, the main driver of economic growth is different. Of course, due to various historical reasons, different countries and regions vary in the time and length of the economic transformation. It is possible that different phases overlap.

Obviously, unified growth theory study the change of the economic growth phase to achieve long-term economic growth from the angle of supply elements. In their opinion, economic transformation is the change of economic growth phase, which is also the meaning of economic transformation we study in this paper. Unified growth theory is more suitable for us to research the long-term sustained growth of current Chinese economy than "troika" theory and the factor determinism.

According to unified growth theory, the five factors influencing the economic growth have taken place great changes in China, which suggests that Chinese economy is going through an important transition period, that is from a growth phase transform to a new growth phase.This paper establishs a Mixed estimate dynamic growth model to empirically test the relationship between the main factors change of economic growth and the regional economic disparities and the economic transformation, which will provide empirical evidence of the transformation of economic growth phase in China. This will provide policy decision-making reference for the economic transformation which aims to achieve long-term sustained growth in China.

\section{Model Setting and Data}

\subsection{Model specification}

Cobb-Douglas production function has good economic connotation and characteristics of mathematical statistics, so it has been widely applied. In terms of the theory logic stated by above literature review, this paper build a dynamic model of the relationship between factors inputs, including labor, physical capital and human capital, and economic growth based on C-D production function. Because it is difficult to be quantified, the total factor productivity is viewed as a parameter. Compared to the Solow's neoclassical growth model, this model has two differences. First, considering the factors of long-term economic growth, we increase the time variable $t$, representing different year. Second, human capital is separated from the Solow residual as an endogenous variables. Human capital is mainly formed through the following ways: education and training, investment in health, "learning by doing" and market experience accumulation. Among those, education-based human capital has significant effects on economic growth, and interacts with health-based human capital. But health-based human capital and education-based human capital are different in many ways, thus the effect of health-based human capital on economic growth is different from that of other human capital. Moreover "learning by doing" and market experience accumulation are difficult to measure. So in this paper human capital is decomposed into two parts: education-based human capital and health-based human capital, and a model is established as follows:

$$
\mathrm{Y}_{\mathrm{it}}=\mathrm{A}_{\mathrm{it}} \mathrm{K}_{\mathrm{it}}{ }^{\alpha \mathrm{t}} \mathrm{L}_{\mathrm{it}}{ }^{\mathrm{Bt}} \mathrm{E}_{\mathrm{it}}{ }^{\psi \mathrm{t}} \mathrm{H}_{\mathrm{it}}{ }^{\mathrm{\delta t}} \mathrm{e}^{\mu \mathrm{it}}
$$

Where $\mathrm{Y}$ is the gross domestic product (GDP), $\mathrm{A}$ is the total factor productivity, a comprehensive index which is characterized by institutional innovation and technological progress

(Jorgenson，2001 ) , $\mathrm{K}$ is the physical capital, $\mathrm{L}$ is the labor, $\mathrm{E}$ and $\mathrm{H}$ are education-based human capital and health-based human capital. Superscripts $\alpha, \beta, \psi, \delta$ are estimated parameters, representing the output elastic coefficient of four independent variables: physical capital, labor, education and health-based human capital. They reflect each factor's relative contribution to economic growth, namely its pull effect on economic growth. The output elasticity multiplied by the growth rate of the factors are the absolute contributions of the factors. $\mu$ is the random error term. $i$ on behalf of the Chinese region variables in three different regions. $t$ is the time variable (representing different years), After taking logarithm of both sides in formula (1), we get a dynamic linear equation as follows: 
$\ln Y_{i t}=C_{i t}+\alpha_{t} \ln K_{i t}+\beta_{t} \ln L_{i t}+\psi t \ln E_{i t}+\delta_{t} \ln H_{i t}+\mu_{i t}$

Where $C_{i t}$ is the new intercept $\ln A, \mu_{i t}$ is random perturbation terms. The advantage of the logarithm model is that the logarithm value of every index is the growth rate of the index. So LnY is the growth rate of $\mathrm{Y} . \alpha \ln \mathrm{K}_{\mathrm{it}}$ is the absolute contribution of capital $\mathrm{K}$ on economic growth. From an economic sense, each factor's contribution to economic growth not only depends on the output elasticity coefficient, but also influenced by the factor's growth rate. Therefore, the relative contribution of the factors can better reflect the dynamic strength of the factor's influence on economic growth than the absolute contribution.

\subsection{The Selection of Indexes and Data Sources}

We select the data from China's 31 provinces, municipalities and autonomous regions from 2003 to 2015, and then sum up to eastern, middle and western regions's panel data in accordance with the area of China's administrative division. Panel data can analyze the phase changes of the main dynamic factors on economic growth which imply the characteristics of the economic transformation from the change of time series, and also can analyze the effect of economic growth factors changes on regional economic disparity from comparison of three cross sections. Finally we can comprehensively analyze economic transformation under the background of regional economic disparity from two dimensions. The sources of each index datum are as follows:

2.2.1 Physical capital

We adopt the international commonly used Goldsmith's perpetual inventory method to calculate the material capital stock. The calculation formula is:

$\mathrm{K}_{\mathrm{t}}=\mathrm{K}_{\mathrm{t}-1}(1-\theta)+\mathrm{I}_{\mathrm{t}} / \mathrm{P}_{\mathrm{t}}$

Where $\mathrm{K}_{\mathrm{t}}$ and $\mathrm{K}_{\mathrm{t}-1}$ represent the capital stock of $\mathrm{t}$ and (t-1) years, $\theta$ represents the depreciation rate of capital, $\mathrm{I}_{\mathrm{t}}$ is the investment in fixed assets of $\mathrm{t}$ year, $\mathrm{P}_{\mathrm{t}}$ is the price index of investment in fixed assets Depreciation rate is from the research of Wang Jinyin(2010), that is $\theta=0.055$. $I_{t}$ and $P_{t}$ are from the China Statistical Yearbook from 2004 to 2016. The material capital stocks of three regions from 2003 to 2015 are calculated by using the formula (3) on the basis of the provincial data calculated by zhang Jun(2004) (unit: one trillion yuan).

\subsubsection{Labor}

According to the number of employment in 31 provinces, municipalities and autonomous regions from 2003 to 2015 in China Statistical Yearbook and local statistical yearbook, we sum up to get eastern, middle and western regions's panel data. (unit: ten thousand).

2.2.3 Education-based human capital

"Average Years of Schooling" is thought by academia as the most reasonable index to measure education-based human capital. We also use the index to calculate average years of schooling of the population aged 15 and above, reflecting human capital stock level in China. According to China's educational system, average years of schooling of those who accept education in college degree or above is 16 years, a high school education is 12 years, junior high school education is 9 years, primary school education is 6 years, and illiterate\& semi-illiterate is 0 year. Due to having no illiterate \& semi-illiterate statistical datum, similar index like " Can't read or read very little " is used to instead of illiteracy \& semi-illiterate. Computation formula is as follows:

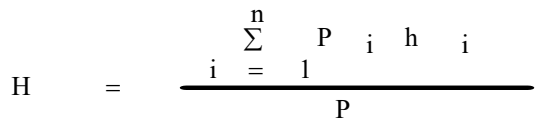

Where $\mathrm{H}$ is average years of schooling who aged 15 and above, $\mathrm{i}$ is the different levels of education, $h_{i}$ is the average years of schooling whose hierarchical level is $I, p_{i}$ is the population of $i$ hierarchical level of education, $\mathrm{P}$ is the total population of different level of education within a certain region for 15 years old and above. Combining with related information in the national population census data, China Statistical Yearbook and China Education Statistical Yearbook from 2004 to 2016, we calculate the average years

2.2.4 Health-based human capital

Health is affected by the innate and acquired factors. Considering the particularity and complexity 
of health-based human capital formation and the availability of statistical data, mortality and life expectancy, nutrition and public health input usually are regarded as the commonly used indexes of health-based human capital in the existing literature. Multiple indexes are also comprehensively used in some literatures. Although using a single index to measure health-based human capital is not very comprehensive, but using multiple indexes to measure will produce the problem that is hard to be quantified. After comparing all indexes, and considering the availability of data, we use the total health expenses as an index of health-based human capital based on the public health input. The data of the total health expenses are from China Statistical Yearbook and 31 provinces (municipalities, autonomous regions) Statistical Yearbook from 2004 to 2016, and referring to some literatures (unit: one trillion yuan).

\subsubsection{Economic growth}

We use the Real GDP to measure economic growth after using GDP implicit price deflator to eliminate the influence of price factor. The data are from China Statistical Yearbook from 2004 to 2016. (unit: one trillion yuan).

\section{The empirical test and results}

\subsection{Unit root test}

If the time series is not steady, it will be tested correlation between two originally independent variables, namely " spurious regression " phenomenon. If so, the empirical research result is of no economic sense. Therefore, unit root test ADF of panel data should be done before regression to determine the stability of data. ADF test are performed through the following three models.

$$
\begin{array}{lrl}
\Delta y_{t} & =\delta y_{t-1}+\sum_{j=1}^{p} \lambda_{j} \Delta y_{t-j}+\mu_{t} & \text { model 1 } \\
\Delta y_{t}=\alpha+\delta y_{t-1}+\sum_{j=1}^{p} \lambda_{j} \Delta y_{t-j}+\mu_{t} & \text { model 2 } \\
\Delta y_{t}=\alpha+\beta t+\delta y_{t-1}+\sum_{j=1}^{p} \lambda_{j} \Delta y_{t-j}+\mu_{t} & \text { model 3 }
\end{array}
$$

Among them, model 1 does not contain constant and trends, model 2 has a constant term, and model 3 contain both constant and trends. The null hypothesis of three models are: $H_{0}: \delta=0$, namely there is a unit root. ADF test begin from model 3, in turn, model 2, and then model 1 . When the null hypothesis is rejected (i.e., the resulting $t$ value is smaller than significant levels under the given threshold), the test will be stopped. Because the original time series is steady in this case. Otherwise, the test of model 2 will be done, until after model 1 test.

We use Eviews 6.0 software to carry on ADF test for time series. The test results are as follows:

table 1 ADF test results of each variable

\begin{tabular}{ccccc}
\hline variables & test method & t statistic & P-value & results \\
\hline \multirow{2}{*}{ LnY } & ADF - Fisher Chi-square & 0.03821 & 1.00000 & unsteadiness \\
& ADF - Choi Z-stat & 4.50650 & 1.00000 & unsteadiness \\
DLnY & ADF - Fisher Chi-square & 49.10820 & 0.00000 & steadiness \\
& ADF - Choi Z-stat & -5.97727 & 0.00000 & steadiness \\
LnK & ADF - Fisher Chi-square & 0.68973 & 0.99470 & unsteadiness \\
& ADF - Choi Z-stat & 2.62620 & 0.99570 & unsteadiness \\
DLnK & ADF - Fisher Chi-square & 10.65990 & 0.09950 & steadiness \\
\hline
\end{tabular}




\begin{tabular}{ccccc}
\hline & ADF - Choi Z-stat & -1.59201 & 0.05570 & steadiness \\
LnE & ADF - Fisher Chi-square & 0.24087 & 0.99970 & unsteadiness \\
& ADF - Choi Z-stat & 3.49475 & 0.99980 & unsteadiness \\
DLnE & ADF - Fisher Chi-square & 25.93860 & 0.00020 & steadiness \\
& ADF - Choi Z-stat & -3.66700 & 0.00010 & steadiness \\
LnL & ADF - Fisher Chi-square & 3.31979 & 0.76780 & unsteadiness \\
& ADF - Choi Z-stat & 0.60660 & 0.72790 & unsteadiness \\
DLnL & ADF - Fisher Chi-square & 15.61360 & 0.01600 & steadiness \\
& ADF - Choi Z-stat & -2.09040 & 0.01830 & steadiness \\
& ADF - Fisher Chi-square & 0.07297 & 1.00000 & unsteadiness \\
LnH & ADF - Choi Z-stat & 3.90778 & 0.69760 & unsteadiness \\
& ADF - Fisher Chi-square & 3.84558 & 0.06031 & steadiness \\
& ADF - Choi Z-stat & 0.26125 & 0.07610 & steadiness \\
\hline
\end{tabular}

Note: If the conclusion is " steadiness ", that said when the significance level is $10 \%$, the time series pass the stationarity test

The prefix $\mathrm{D}$ variables in table 2 on behalf of the first order differential sequence. Take the stationarity test of LnY for example, The t test statistics of ADF - Fisher Chi - square and ADF Choi Z - stat are 0.03821 and 4.50650. They are greater than the significance level of $10 \%$. At the same time, the $\mathrm{P}$ values of the test are greater than 0.1 . The results show that the original time series has unit root, so LnY sequence is not steady. A stationarity test of the first order differential sequence DLnY is needed to be performed. After stationarity testing, the t test statistics of ADF Fisher Chi - square and ADF - Choi Z - stat are less than the significance level of $10 \%$, and the P values of the test are less than 0.1 , namely the first order differential sequence DLnY is stationary series. Similarly, LnK, LnL, LnE, LnH series are not steady, but DLnK, DLnL, DLnE, DLnH series are stationary series.

\subsection{Co-integration test}

Although DLnK, DLnL, DLnE, DLnH series are stationary series, it may still have a " spurious regression " problem if we use first-order difference stationary series for regression analysis. Because unit root test will lost long-term and useful information which variables may contain. So further co-integration test is needed to eliminate "spurious regression" in order to explain the significance of regression results. According to the requirement of co-integration test, at least two variables are need. And integration order of explanatory variables should be greater than or equal to integration order of explained variables. When there are at least two explanatory variables, their integration order must be consistent. Above unit root test confirms that every economic variables are integrated of order 1, so co-integration test can be performed. We establish a null hypothesis: there is no co-integration relationship within variables, and then use panel data to get the residuals statistics to perform test. We use Eviews 6.0 software to carry on the co-integration test, and then get the following results: 
Table 2 cointegration test results

\begin{tabular}{ccc}
\hline & t-Statistic & Prob. \\
\hline ADF & -5.421039 & 0.0000 \\
Residual Variance & 0.000645 & \\
HAC Variance & 0.000564 & \\
\hline
\end{tabular}

From the test results of co-integration, the $\mathrm{P}$ value corresponding to ADF significantly lower than 0.05 , therefore, the null hypothesis is rejected. That said there is long-term stable equilibrium relationship within variables. Next step, regression analysis can be carried on.

\subsection{Model selection}

Before the regression analysis, $\mathrm{F}$ test of panel data is needed to determine what kind of model will be set up. Mixed estimation model refers to what there is no significant difference between individuals of different time series, and between different sections. The OLS method of least squares can be directly used to perform the panel data regression estimate to get the parameters. Entity fixed effects regression model refers to what there is different intercept for different time series and different sections. So a dummy variable is needed to be added in the model to estimate parameters. First of all, we establish the following hypothesis:

$\mathrm{H}_{0}$ : models have the same intercepts for different cross sections $\quad a_{i}=a$ (setting up mixed estimation model)

$\mathrm{H}_{1}$ : models have different intercepts for different cross sections

(setting up entity fixed effects model)

$F$ test results are shown in table 4:

Table $3 \mathrm{~F}$ test result of panel data

\begin{tabular}{cccc}
\hline Effects Test & Statistic & d.f. & Prob. \\
\hline Cross-section F & 0.149795 & $(2,15)$ & 0.8622 \\
Cross-section Chi-square & 0.593275 & 2 & 0.7433 \\
\hline
\end{tabular}

According to the data in table $4, \mathrm{~F}=0.14979<\mathrm{F}_{0.05}(2,15)=3.68$, the null hypothesis $\mathrm{H}_{0}$ is accepted. A mixed estimation model should be established, namely the individual's parameters $C_{t}$ 、 $\alpha_{\mathrm{t}} 、 \beta_{\mathrm{t}}, \psi_{\mathrm{t}}, \delta_{\mathrm{t}}$ are the same for different time series and cross sections, so the model is:

$\ln Y_{i t}=C+\alpha \ln K_{i t}+\beta \ln L_{i t}+\psi \ln E_{i t}+\delta \ln H_{i t}+\mu_{i t}$

\subsection{The analysis of regression results}

We use Eviews 6.0 software to carry on OLS method of least square regression for regional panel data. And EAST, MIDD and WEST on behalf of regional variables i. The regression results are as follows:

Table 4 The regression results of correlation between factors and the regional economic growth

\begin{tabular}{|c|c|c|c|c|}
\hline \multicolumn{5}{|c|}{ Dependent Variable: Y? } \\
\hline \multicolumn{5}{|c|}{ Method:Pooled Least Squares } \\
\hline \multicolumn{5}{|c|}{ Sample: 20032013} \\
\hline \multicolumn{5}{|c|}{ Included observations: 11} \\
\hline \multicolumn{5}{|c|}{ Total pool(balanced)observations: 33} \\
\hline Variable & Coefficient & Std. Error & t-Statistic & Prob. \\
\hline EAST--C & 6.290550 & 5.993122 & 1.049628 & 0.3105 \\
\hline MIDD--C & 4.336851 & 5.746275 & 0.754724 & 0.4621 \\
\hline WEST--C & 2.761627 & 2.934889 & 0.940965 & 0.3616 \\
\hline
\end{tabular}




\begin{tabular}{|c|c|c|c|c|}
\hline EAST--K & 0.253816 & 0.231707 & 1.095419 & 0.2905 \\
\hline MIDD--K & 0.307328 & 0.103383 & 2.972688 & 0.0095 \\
\hline WEST--K & 0.264805 & 0.075937 & 3.487188 & 0.0033 \\
\hline EAST--L & -0.429698 & 0.873966 & -0.491663 & 0.6301 \\
\hline MIDD--L & -0.062550 & 0.588773 & -0.106238 & 0.9168 \\
\hline WEST--L & 0.049936 & 0.349925 & 0.142703 & 0.8884 \\
\hline EAST--E & 2.428118 & 1.746893 & 1.389963 & 0.1847 \\
\hline MIDD--E & 1.135793 & 0.420143 & 2.703355 & 0.0163 \\
\hline WEST--E & 1.702299 & 0.803676 & 2.118139 & 0.0513 \\
\hline EAST--H & 0.161529 & 0.316910 & 0.509702 & 0.6177 \\
\hline MIDD--H & 0.119722 & 0.130212 & 0.919436 & 0.3724 \\
\hline WEST--H & 0.106496 & 0.132456 & 0.804016 & 0.4338 \\
\hline R-squared & 0.998982 & \multicolumn{2}{|c|}{ Mean dependent var } & 11.04887 \\
\hline Adjusted R-squared & 0.998035 & \multicolumn{2}{|c|}{ S.D. dependent var } & 0.600485 \\
\hline S.E. of regression & 0.026598 & \multicolumn{2}{|c|}{ Akaike info criterion } & -4.109095 \\
\hline Sum squared reside & 0.010612 & \multicolumn{2}{|c|}{ Schwarz criterion } & -3.408497 \\
\hline Log likelihood & 76.63643 & \multicolumn{2}{|c|}{ Hannan-Quinn criter. } & -3.884968 \\
\hline F-statistic & 1054.703 & \multicolumn{2}{|c|}{ Durbin-Watson stat } & 1.778585 \\
\hline Prob(F-statistic) & 0.000000 & & & \\
\hline
\end{tabular}

Note: All parameter estimation of $\mathrm{t}$ test pass test under $5 \%$ significance level.

Regression results show that $\mathrm{R}^{2}=0.998982$ and adjusted $\mathrm{R}^{2}=0.998035$, which mean the model has better goodness-of-fit. The F test statistics of the Model is 1054.7, and P value is 0 , which mean all the interpretation degrees of the independent variable are higher. The model passes the significance test. The regression equations are:

The eastern Region: $\ln Y=6.29+0.25 \ln \mathrm{K}-0.43 \ln \mathrm{L}+2.43 \ln \mathrm{E}+0.16 \ln \mathrm{H}$

The middle Region: $\ln Y=4.34+0.31 \operatorname{lnK}-0.06 \ln \mathrm{L}+1.14 \ln \mathrm{n}+0.12 \ln \mathrm{H}$

The western Region: $\ln \mathrm{Y}=2.76+0.26 \ln \mathrm{K}+0.05 \ln \mathrm{L}+1.70 \ln \mathrm{E}+0.11 \ln \mathrm{H}$

The sum of the output elasticity of four independent variables is greater than 1, which shows that China's economic growth is in the phase of increasing Returns to Scale.

Regression results show that:

(1) In three regions, the correlation coefficient of four independent variables K, L, E, H , namely the output elasticity of each factor, from big to small in turn is: education-based human capital, physical capital, health-based human capital, labor. This indicates that, Since 2003, each factor's driving effect on economic growth has changed obviously in China. Education-based human capital has become the first driving force on economic growth. Its correlation coefficients in eastern, middle and western China are 2.428, 1.136, 1.702 respectively, which means $1 \%$ growth of average years of schooling will drive eastern, middle and western China to grow $2.428 \%, 1.136 \%$ and $1.702 \%$ respectively. And its leading role on economic growth is better than the effect of other factors. The pull role of health-based human capital on economic growth is far smaller than that of education-based human capital, because the correlation coefficients in eastern, middle, western China are only $0.16,0.12,0.11$.

(2) That physical capital's long-term effect on Chinese economy also cannot be ignored. 
Although its effect on economic growth is far less than that of human capital, but the output elastic coefficients in three regions also reach $0.254,0.307,0.265$ respectively. It is still the second driving factor on economic growth. In middle and western China, especially in middle region, economic growth more depends on material capital investment than that in eastern region.

(3) The effect of labor input on economic growth take a back seat in the end and is smallest among all factors. The correlation coefficient of labor are negative in eastern and middle China, being -0.430 and -0.06 respectively, while there is a positive correlation coefficient in western China. But the correlation coefficient is only 0.05 in western region, which shows that its impact on western China's economic growth is not significant. This turning point indicates that labor in eastern and middle China is relatively surplus relative to the existing technical level and physical capital. Labor input has entered a phase of diminishing marginal returns. The result is the same as the industrial structure upgrade and the change of production input way observed by us under the background of the demographic transition in China.

(4) The parameter $C$ value are bigger in three regions, being 6.29,4.34,2.76, which shows total factor productivity is the important factor that affect regional economic growth. Its effect on eastern region is largest, and in turn, decreasing in middle, western regions. This also reflects that there is a larger gap of institutional environment and technological level within three regions.

(5) From the comparison of absolute datum of each index and regression equations, the regional differentiation is serious although the overall change trend is consistent in three regions. Except for physical capital, there is a gap on other factors within three regions, which shows that there exists macro-misallocation of factors within regions and regional development gap. Education-based human capital and total factor productivity are main factors which cause regional economic disparities. Health-based human capital, physical capital investment and labor have a little effect on disparity of regional economic growth.

Above results based on Chinese empirical evidence explains the thought about the relationship between the change of growth phase caused by the main factors change on economic growth and economic transformation presented by Galor and Weil (2000).

But compared with developed countries, level of human capital investment in China is still very low.

\section{Conclusions}

Unified growth theory analyzes economic endogenous transformation with the change of economic growth phase, and the transformation of economic growth phase is caused by the change of the main dynamic factors on economic growth. When a country's demographic dividend begins to reduce, the main driver of economic growth turns to per capita productivity. The methods of improving per capita productivity include capital investment, human capital investment, and improving total factor productivity. This paper supports these ideas based on China's empirical data from 2003 to 2015.

The empirical results show that the dynamic structure of main growth factors has changed. China is transforming from after-Malthusian growth phase to a modern economic growth phase, in which demographic transition will play an important role. And regional differentiation is significant. The change of economic growth phase means that the original production system and economic system have become increasingly unable to adapt to new change. At present, China's short-term potential growth rate is facing a downward trend affected by reducing labor supply, weakening capital driving force and falling export growth, which is the cost of an economic structural slowdown Chinese economy must pay in the process of economic transformation. Therefore, in order to promote China's economic transformation and long-term economic growth, a new economic system must be reconstructed, for which it is inevitable choices for China to increase human capital investment and improve total factor productivity. Chinese economic transformation should be advanced according to the order based on the reality of regional economic disparity. 


\section{References}

[1] [2] D $\cdot \mathrm{W} \cdot$ Jorgensen. Productivity (Vol.2) [M], China's development publishing house,2001. (In Chinese)

[2] [5] Hu Wenguo, Wu dong. Theory and empirical analysis of China's economic growth factors [J],Journal of Tsinghua University, 2004(4) . (In Chinese)

[3] [13] Wang Jinyin. The human capital and economic growth: theory and empirical study[M], China financial and economic publishing house,2010. (In Chinese)

[4] [14] Zhang Jun, Wu Guiying, Zhang Jipeng . China's provincial material capital estimates: 1952-2000 [J], Economic Studies, 2004(10) . (In Chinese)

[5] [21] Galor, O.\&D.Weil,2000, "Population, technology, and growth: From Malthusian stagnation to the demographic transition and beyond", American Economic Review, vol.90, pp.806-828.

[6] [22] Galor, O.,2008, "Towards a unified theory of economic growth", World Economics, vol.9, pp.97-151. 